\title{
Mikroçoğaltımla Üretilmiş Fesleğenin (Ocimum basilicum L.) Tepsili Kurutucuda Kuruma Karakteristiğinin Belirlenmesi
}

\author{
Aykut TOPDEMIR* \\ Fırat Üniversitesi Mühendislik Fakültesi Biyomühendislik Bölümü, Elazı̆̆ \\ atopdemir@firat.edu.tr
}

(Geliş/Received: 20/05/2019;

Kabul/Accepted:29/08/2019)

Öz: Bu çalışmada mikroçoğaltım ile in vitro ortamda elde edilen, tıbbi ve aromatik öneme sahip Ocimum basilicum L. türüne ait bitki örneklerinin tepsili kurutucuda kuruma karakteristiği incelenmiştir. Tarımsal ürünlerin hasat sonrası işlemlerinin başında kurutma gelmektedir. Özellikle tıbbi ve aromatik öneme sahip olan bitkiler kurutma proseslerine tabi tutulmaktadır. Endüstriyel proseslerde kurutucu olarak tepsili kurutucu yaygın olarak kullanılmaktadır. Deneyler 3 farklı sıcaklık $\left(30-50{ }^{\circ} \mathrm{C}\right)$ ve 3 farklı akış hızında $(0.5-1.5 \mathrm{~m} / \mathrm{s}) 3$ tekrarlı olacak şekilde gerçekleştirilmiştir. Deneyler sonucunda, mikroçoğaltımla üretilmiş Ocimum basilicum L örneklerinin azalan hız periyodunda kuruma sergilediği gözlenmiştir. Düşük sıcaklıklarda hava akış hızının difüzyon katsayısına etkisinin olmadığı, fakat yüksek sıcaklıklarda artan hava hızı ile difüzyon katsayısının arttığı belirlenmiştir. Çalışılan tüm hava hızlarında artan sıcaklıkla beklenildiği gibi difüzyon katsayısının arttığı sonucuna ulaşılmıştır.

Anahtar kelimeler: Tepsili kurutucu, Ocimum basilicum L., mikroçoğaltım, etkin difüzyon katsayısı.

\section{Determination of Drying Characteristics of Basil (Ocimum basilicum L.) Produced by Micropropagation in Tray Dryer}

\begin{abstract}
In this study, drying characteristics of plant samples, having medicinal and aromatic importance, belonging to Ocimum basilicum L. species obtained from micro-propagation and in vitro environment were examined in tray dryer. Tray dryer is widely used as a dryer in industrial processes. The experiments were carried out with three replications at three different temperatures $\left(30-50^{\circ} \mathrm{C}\right)$ and three different flow rates $(0.5-1.5 \mathrm{~m} / \mathrm{s})$. As a result of the experiments, it was observed that Ocimum basilicum L. samples produced by micro-propagation showed drying in decreasing speed period. It was determined that airflow rate had no effect on the diffusion coefficient at low temperatures, but diffusion coefficient raised with increasing air velocity at high temperatures. It was concluded that the diffusion coefficient increased as expected with increasing temperature at all air velocities studied.
\end{abstract}

Key words: Tray dryer, Ocimum basilicum L., micropropagation, effective diffusivity.

\section{Giriş}

Gıda maddelerinin kurutulmasında kullanılan en basit yöntem güneş enerjisi ile açık havada gerçekleştirilen kurutma tekniğidir. Ancak bu şekilde yapılan kurutma işleminin mikrobiyal açıdan pek çok olumsuzluğu söz konusu olmaktadır. Endüstriyel olarak gerçekleştirilen kurutma işlemlerinden en çok kullanılan kurutma prosesleri sıcak havanın kullanıldığı proseslerdir [1-8]. Kurutma proseslerinin en önemli basamaklarından biri kabul edilen ve yaygın olarak kullanılan sıcak havayla (konvektif) kurutma prosesi vasitasıyla, ürün kalitesinde herhangi bir bozulmaya olanak tanımadan, ürünün nemi en kısa sürede ve en az enerji harcanarak son nem değerine düşürülmektedir. Kurutma havasının sıcaklığı üründen ürüne değişmekle birlikte tıbbi ve aromatik bitkilerde 30 ile $50{ }^{\circ} \mathrm{C}$ arasinda olması gerekmektedir [9-11].

Tıbbi ve aromatik bitkiler; beslenme, sağlığı sürdürme ve koruma, hastalıkları önleme ve tedavi etme, güzel koku, tat ve çeşni sağlama amacıyla oldukça yaygın olarak kullanılmaktadır [12]. Ocimum basilicum L. (fesleğen) baharat ve ilaç olarak kullanılan tek yıllık aromatik ve hoş kokulu bir bitkidir. O. basilicum L. bitkisinin içinde barındırdığı faydalı özellikler ve kullanım alanlarındaki ihtiyaçlar göz önüne alındığında daha geniş alanlarda tarımının yapılması gereklidir. $O$. basilicum $\mathrm{L}$. tohumunun çok küçük oluşu makinalı hassas ekime olanak tanımamaktadır. Fide yetiştirme zorlukları nedeniyle de ülkemizde $O$. basilicum L. üretiminin yeteri kadar yapılamadığı bilinmektedir [13]. Çoğaltım, bitkilerin sürekliliğini sağlamak için onların kontrollü olarak üretilmesidir. Generatif (eşeyli) ve vejetatif (eşeysiz) çoğaltma olmak üzere iki şekilde gerçekleşir. Eşeyli

\footnotetext{
* Sorumlu yazar: atopdemir@firat.edu.tr. Yazarın ORCID Numarası: 0000-0002-9112-4767
} 
(generatif) çoğaltma, tohum kullanılarak gerçekleşen çoğaltma çeşididir. Pek çok bitki türü çok kompleks genetik bir yapıya sahip olduğu için, bu türlerin

tohumlarından üretilen bitkiler özellikleri yönüyle birbirlerine benzemezler ve genellikle yabani olan türlerine benzerler.

Eşeysiz (Vejetatif) çoğaltma ise, kök, yaprak, sürgün, farklılaşmış gövde ve kökler gibi bitki kısımları ile gerçekleştirilen çoğaltma şeklidir. Vejetatif çoğaltma ile üretilen bitkilerin kalıtsal yapısında hiçbir değişiklik gözlenmez ve ana bitkinin kalıtsal özellikleri tamamen yavru bitkiye geçer. Vejetatif çoğaltma; çelik, aşı, daldırma tekniği, farklılaşmış gövde ya da kök kısımları (yumru, soğan, rizom gibi), doku kültürü teknikleri (mikroçoğaltım) gibi farklı yöntemlerle yapılabilir [14]. Mikroçoğaltım, bir bitkiden alınan ve tam bir bitkiyi oluşturabilme potansiyeline sahip bitki kısımlarından yapay olarak hazırlanan besin ortamlarında ve mikroorganizmalardan arındırılmış şartlar altında genetik olarak birbirine benzeyen çok sayıda bitkiyi hızlı çoğaltmak için tercih edilen bir doku kültürü tekniğidir.

Bu çalışmada, mikroçoğaltım ile in vitro ortamda elde edilen $O$. basilicum L. bitkisini, tepsili kurutucuda farklı sıcaklık ve hava akış hızlarında kuruma karakteristiğinin belirlenmesi amaçlanmıştır.

\section{Materyal ve Metot}

\subsection{Materyal}

Deneysel çalışmalarda kullanılan ve Elazığ ili Sivrice ilçesi Güney köyü mevkiinden toplanan $O$. basilicum L. bitkisi Fırat Üniversitesi Mühendislik Fakültesi Biyomühendislik Bölümü Bitki Doku Kültürü laboratuvarında mikroçoğaltım yöntemiyle üretilmiştir. Besiyeri olarak Murashige Skoog (MS) besiyeri, bitki büyüme düzenleyicisi (BBD) olarak $0.5 \mathrm{mg} / \mathrm{L}$ Kinetin $-0.5 \mathrm{mg} / \mathrm{L}$ 2,4-Dichlorophenoxyacetic acid ve \% 0.8 ' lik plant agar kullanılmıştır. [15]. O. basilicum L. fidelerinden elde edilen gövdeler steril bir bisturiyle alındıktan sonra ilk olarak musluk suyuyla yıkanıp kültüre alınmadan önce 30 saniye \%70'lik etil alkolde bekletilmiştir. Etil alkolden süzülen bitki eksplantları alkollenerek kabin içerisine alınmıştır. 5 dakika $\% 50$ oranda saf su ile seyreltilmiş sodyum hipokloritte $(\mathrm{NaClO})$ bekletilmiştir. Sodyum hipoklorit olarak \% 5 'lik ticari çamaşır suyu kullanılmışstır. Bitki eksplantlarına, sodyum hipokloritin yüzeye olan temasını arttırmak için bekletilmeleri sırasında 1-2 damla tween maddesi eklendi. 1.5 - $2 \mathrm{~cm}$ aralı̆̆ındaki farklı uzunlukta $O$. basilicum L., gövdeleri BBD içeren besi yerlerine aktarıldı. Sürgünler 4 hafta boyunca her gün 16 saat 3000 lüks 1şık ve 8 saat karanlıkta $24 \pm 1^{\circ} \mathrm{C}^{\prime}$ de köklendirme ortamı üzerinde inkübe edildi. Mikroçoğaltımın son aşaması olarak bilinen aklimatizasyon sürecinde; köklenmesini tamamlayan $O$. basilicum L. bitkileri dikim ortamlarına ve çevre koşullarına kademeli olarak alıştırılması için adapte edildi. Köklendirme ortamlarından alınan bitkiler, besi ortamından çıkarıldıktan sonra musluk suyunda yıkanarak besi ortamından tamamen arındırılması sağlandı. Dikim ortamı olarak kullanılan materyal (torf), otoklavda $121^{\circ} \mathrm{C}^{\prime}$ de $15 \mathrm{dk}$ süreyle steril edildikten sonra bu toprağa $1: 1$ oranında perlit ilave edilerek saksılara pay edildi. Hazır hale getirilen bu saksılara köklenme sürecini tamamlamış olan $O$. basilicum L. bitkileri ekildi.

\subsection{Tepsili Kurutucu Deneyleri}

Deneysel çalışmalar Furat Üniversitesi Biyomühendislik Bölümü laboratuvarında mevcut olan ve Şekil 1'de gösterilen deney setinde gerçekleştirildi. Deney seti başlıca serpantenli 1sıtıcı, fan, terazi ve bilgisayar sisteminden oluşmaktadır. Ocimum basilicum L. örneklerinin başlangıç nem içerikleri Mettler LJ16 marka infrared kurutucuda ölçüldü. Deneylerin her birinde $5 \mathrm{~g}$. yaprak miktarı kullanılddı. Çalışma sıcaklıkları sırasıyla 30,40 ve $50{ }^{\circ} \mathrm{C}$ olacak şekilde ayarlandı. Her bir sıcaklık değeri için $0.5,1$ ve $1.5 \mathrm{~m} / \mathrm{s}$ hava akış hızlarında kurutma işlemi yapıldı. Deneysel çalışmalar örneklerin 10 'ar dakika aralıklarla tartım değerleri alınarak yürütüldü. İki tartım değeri arasındaki fark $\% 0.5$ oluncaya kadar tartım işlemine devam edildi.

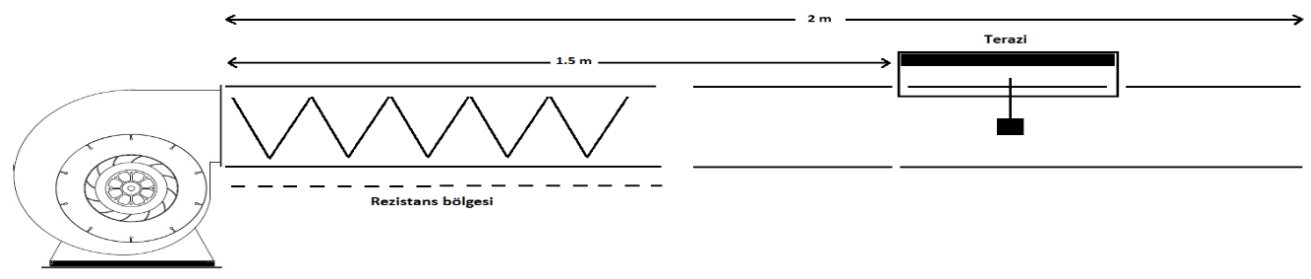

Şekil 1. Tepsili kurutucu sistemi. 


\section{Bulgular}

Fesleğenin kuruma karakteristiğinin incelendiği bu çalışmada 30,40 ve $50^{\circ} \mathrm{C}$ 'de farklı hava akış hızlarındaki kuruma eğrileri (zaman-nem içeriği (w) grafiği) Şekil 2'de gösterilmiştir.

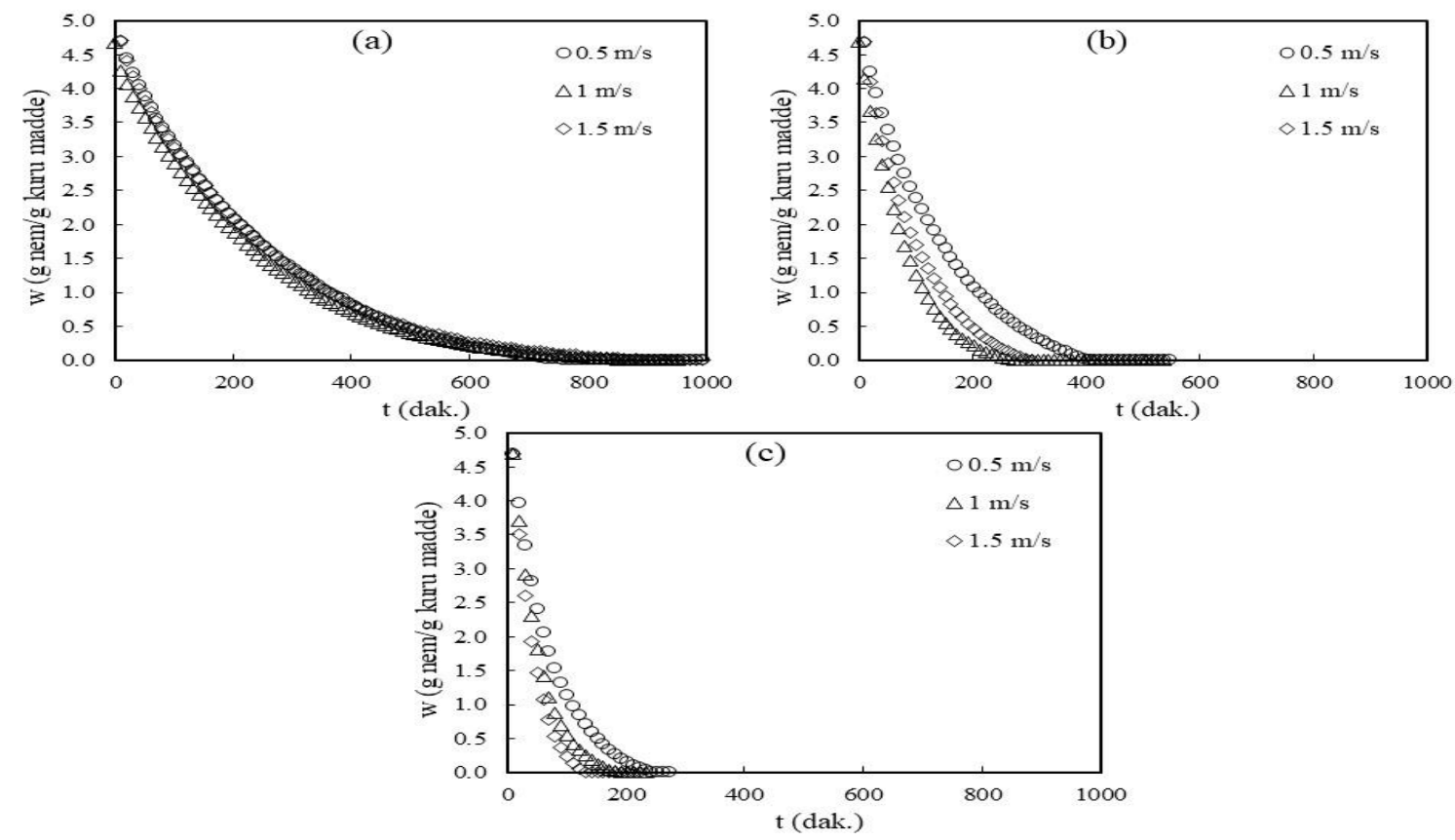

Şekil 2. Mikroçoğaltım ile üretilmiş $O$. basilicum L. örneklerinin çalışılan sıcaklıklarda (a: $30^{\circ} \mathrm{C}$, b: $40^{\circ} \mathrm{C}$, c: $\left.50^{\circ} \mathrm{C}\right)$ farklı hava akış hızlarındaki kuruma eğrileri.

\section{Sonuçlar ve Tartışma}

Deneylerde kullanılan tüm örneklerin başlangıç nem içeriği değerleri \%82.4 olarak ölçülmüştür. Şekil 2'den çalışılan tüm sıcaklık ve hava akış hızlarında zamanla Mikroçoğaltım ile üretilmiş $O$. basilicum L. örneklerinin nem içeriği değerleri azaldığı ve belirli bir süre sonra örneklerdeki nemin tamamen uzaklaştı̆̆ görülmektedir. Şekil 2'den ayrıca sıcaklığın artmasıyla nem içeriği değerlerinin sıfıra yaklaşma zamanı değerlerinin daha kısa sürelerde gerçekleştiği de gözlenmektedir. $30{ }^{\circ} \mathrm{C}$ 'de 750 . Dakikalarda nemin tamamen uzaklaşması, 40 ve 50 ${ }^{\circ} \mathrm{C}$ 'de sırasıyla 400. ve 200. dakikalarda gerçekleşmiştir. Çalışılan sıcaklıklarda hava akış hızının kuruma olayını özellikle düşük sıcaklıkta $\left(30^{\circ} \mathrm{C}\right)$ pek fazla etkilemediği Şekil 2'den elde edilen bir diğer sonuçtur. Elde edilen kuruma eğrileri literatürde farklı materyallerin kurutulmasında elde edilen tipik kuruma eğrileriyle uyumludur [16$18]$.

Bu çalışmada elde edilen kuruma verilerinden kuruma hızı $(w-d w / d t)$ grafikleri de oluşturulmuştur. Şekil 3 'te gösterilen bu grafiklerden kuruma olayı için hız periyodunu belirlemek mümkündür [19,20]. Şekil $3 a^{\prime}$ da $30^{\circ} \mathrm{C}$ 'de farklı hava akış hızlarındaki kuruma hızı eğrileri görülmektedir. Hava akış hızının etkisinin kuruma hızına etkisinin neredeyse olmadığı kuruma hızı eğrilerinden de gözlenmektedir. Bu kuruma hızı grafiğinden çok az da olsa iki aşamalı azalan hız periyodunda bir kuruma olayının gerçekleştiği söylenebilir. Şekil 3b ve 3c'de ise tek aşamalı azalan hız periyodunda bir kuruma olayının gerçekleştiği çok açıktır. Bunun yanında hava akış hızı çalışılan daha yüksek sıcaklık değerlerinde farklı kuruma hızı eğrilerinin oluşmasına yol açmıştır. Fakat, bu etki çok da belirgin bir değişim şeklinde değildir.

Literatürde azalan hız bölgesinde katıdaki nem transferinin Fick'in ikinci yasası ile açıklanabileceği belirtilmiştir [21]. Fick'in ikinci yasasının tek yönlü difüzyon için matematiksel ifadesi çözümünden aşağıdaki denklem elde edilir:

$$
\ln \frac{w-w_{e}}{w_{0}-w_{e}}=\ln (M)=\ln \left(\frac{8}{\pi^{2}}\right)-\frac{D_{e f f} \pi^{2}}{L^{2}} t
$$


Burada, $w_{0}$ ve $w_{e}$ sırasıyla başlangıç ve denge anındaki nem içerikleri, $M$ boyutsuz ayrılabilir nem oranı, $D_{e f f}$ suyun katıdaki difüzyon katsayısı, L katı içerisinde difüzyonun gerçekleştiği boyutun kalınlığı, t kuruma süresidir. Denklem 1'e bakıldığında $t$ - $\ln M$ grafiği lineerdir ve eğimden $D$ etkin difüzyon katsayısı hesaplanabilir. Bu şekilde oluşturulan $30^{\circ} \mathrm{C}$ 'de çalışılan hava akış hızlarındaki bir grafik Şekil 4 'te gösterilmiştir.
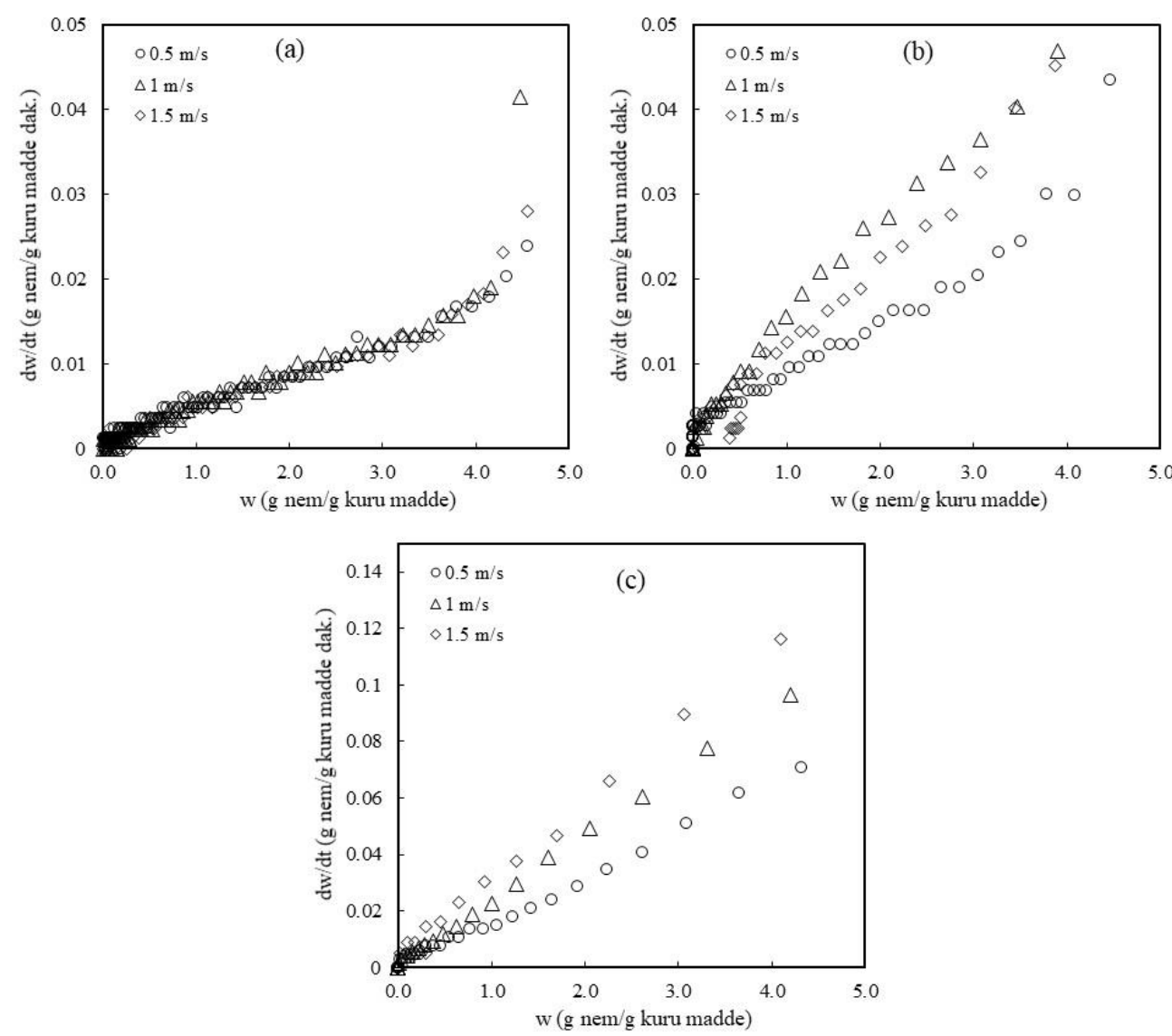

Şekil 3. Mikroçoğaltım ile üretilmiş $O$. basilicum L. örneklerinin çalışılan sıcaklıklarda (a: $30^{\circ} \mathrm{C}$, b: $40{ }^{\circ} \mathrm{C}$, c: $\left.50{ }^{\circ} \mathrm{C}\right)$ farklı hava akıș hızlarındaki kuruma hızı eğrileri

Şekil 4'den görüldüğü gibi logaritmik kuruma eğrileri lineerdir. Böylece, Mikroçoğaltım ile üretilmiş $O$. basilicum L. örneklerinin kurumasına ilişkin etkin difüzyon katsayıları hesaplanmıştır. Hesaplamalarda kullanılan kuruma mesafesi $(L)$ yaklaşık olarak $1 \mathrm{~cm}$ olarak ölçülmüştür.

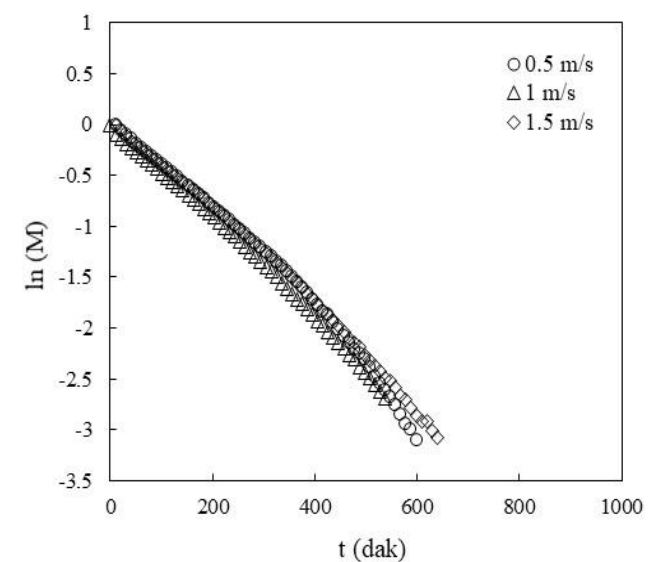

Şekil 4. Farklı kurutma sıcaklıklarında Mikroçoğaltım ile üretilmiş $O$. basilicum L. örneklerine ait logaritmik kuruma eğrileri 
Çalışılan diğer sıcaklıklardaki logaritmik kuruma eğrileri de Şekil 4’tekine benzer olarak elde edilmiştir. Mikroçoğaltım ile üretilmiş $O$. basilicum L'nin farklı sıcaklık ve hava akış hızlarındaki kuruma verilerinden faydalanarak $t$ - $\ln M$ grafiklerinden hesaplanan etkin difüzyon katsayısı ve $R^{2}$ değerleri Tablo 1 'de verilmiştir.

Tablo 1. Mikroçoğaltım ile üretilmiş $O$. basilicum L'nin farklı sıcaklık ve hava akış hızlarındaki etkin difüzyon ve regrasyon katsayısı değerleri.

\begin{tabular}{|c|c|c|c|c|c|c|}
\hline \multirow{2}{*}{$\begin{array}{c}\text { Sicaklık } \\
\left({ }^{\circ} \mathbf{C}\right)\end{array}$} & \multicolumn{6}{|c|}{ Hava akış hızı $(\mathbf{m} / \mathbf{s})$} \\
\hline & 0.5 & \multicolumn{2}{|c|}{1} & \multicolumn{2}{c|}{1.5} \\
\hline & $D_{\text {eff }}\left(\mathrm{m}^{2} / \mathrm{s}\right) \times 10^{10}$ & $R^{2}$ & $D_{\text {eff }}\left(\mathrm{m}^{2} / \mathrm{s}\right) \times 10^{9}$ & $R^{2}$ & $D_{\text {eff }}\left(\mathrm{m}^{2} / \mathrm{s}\right) \times 10^{9}$ & $R^{2}$ \\
\hline 30 & 8.452 & 0.988 & 8.114 & 0.996 & 8.452 & 0.995 \\
\hline 40 & 14.341 & 0.988 & 2.738 & 0.997 & 2.163 & 0.995 \\
\hline 50 & 29.075 & 0.989 & 4.192 & 0.997 & 5.206 & 0.998 \\
\hline
\end{tabular}

Tablo 1'deki sonuçlar incelendiğinde tüm çalışma şartlarında oldukça yüksek $\mathrm{R}^{2}$ değerlerinin elde edildiği görülmektedir. Mikroçoğaltım ile üretilmiş $O$. basilicum L'nin difüzyon katsayısı değerlerinin $\left(10^{-10}\right)$ literatürde O. basilicum türü için yapılan bir çalışmadaki difüzyon katsayısı ile yaklaşık olarak aynı mertebelerde olduğu söylenebilir [17]. Tablo 1 'den $30^{\circ} \mathrm{C}^{\prime}$ de hava akış hızıyla difüzyon katsayısı değerlerinin pek değişmediği görülmektedir. Bununla beraber, 40 ve $50^{\circ} \mathrm{C}$ 'de hava akış hızıyla difüzyon katsayısının genellikle arttığı sonucuna ulaşılmıştır. Çalışılan tüm hava hızı değerlerinde sıcaklık arttıkça beklenildiği gibi etkin difüzyon katsayılarının da arttı̆̆ Tablo 1'den elde edilen bir diğer sonuçtur.

\section{Semboller}

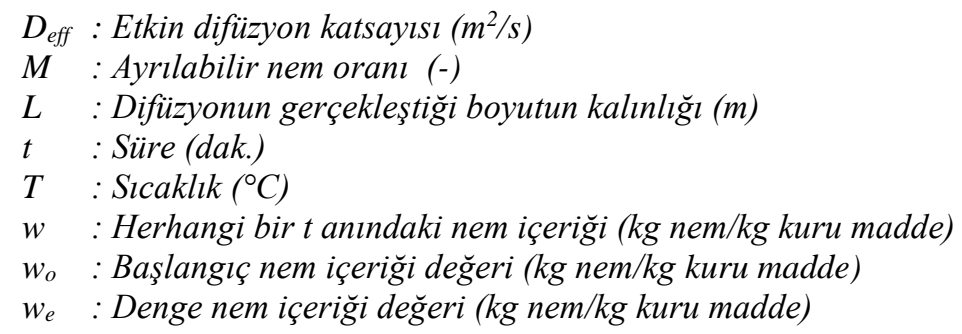

\section{Kaynaklar}

[1] Kalender, M., Akosman, C. Infrared Kurutucuda Ayçiçeği Tohumlarının Kuruma Davranış1 ve Kuruma Modellerine Uyum Analizi. Frrat Üniv. Mühendislik Bilimleri Dergisi 2015; 27(1), 51-56.

[2] T.C. Gıda, Tarım ve Hayvancılık Bakanlığı Bitkisel Üretim Genel Müdürlüğ̈̈ (BÜGEM) Faaliyetleri Verileri. http://www.tarim.gov.tr/sgb/Belgeler/SagMenuVe riler/BUGEM.pdf (Son erişim tarihi: 27.02.2015)

[3] De Figueiredo, A., Baümler, E., Riccobene, I., Nolasco, S. Moisture-dependent engineering properties of sunflower seeds with different structural characteristics. Journal of food engineering 2011; 102, 58-65.

[4] Pereyra-Irujo, G.A., Aguirrezábal, L.A. Sunflower yield and oil quality interactions and variability: Analysis through a simple simulation model. Agricultural and forest meteorology 2007; 143, 252-265.

[5] Georgogianni, K., Kontominas, M., Pomonis, P., Avlonitis, D., Gergis, V. Conventional and in situ transesterification of sunflower seed oil for the production of biodiesel. Fuel Processing Technology 2008; 89, 503-509.

[6] Antolın, G., Tinaut, F., Briceno, Y., Castano, V., Perez, C., Ramırez, A. Optimisation of biodiesel production by sunflower oil transesterification. Bioresource technology 2002; 83, 111-114.

[7] Seifi, M. R. \& Alimardani, R. Moisture-dependent physical properties of sunflower seed. Modern Applied Science 2010; 4, 135-143.

[8] Darvishi, H., Azadbakht, M., Asl, A.R. Experimental Analysis of Moisture Transfer during Thin layer Drying of Black Sunflower Seeds. International Journal of Agricultural and Food Science 2012; 2, 103-17.

[9] Müller J. Convective Drying of Medicinal, Aromatic, and Spice Plants: a Review. Stewart Postharvest Review 2007; $4: 2,1-7$.

[10] İnan, E., Tarhan, S.Yeni Tip Doğrudan Değmeli Kurutucunun Geliştirilmesi ve Reyhan (Ocimum basilicum L.) Bitkisini Kurutma Performansının Belirlenmesi. Tarım Bilimleri Araştırma Dergisi 2012; 5 (2): 151-155.

[11] Güngör, A. Sebze Ve Meyve Kurutmada Kullanılan Kurutucular Ve Kurutma Teknolojileri. 11. Ulusal Tesisat Mühendisliği Kongresi 17-20 Nisan 2013; İzmir, Türkiye.

[12] Faydaoğlu, E., Sürücüoğlu, M.S. Geçmişten Günümüze Tıbbi ve Aromatik Bitkilerin Kullanılması ve Ekonomik Önemi. Kastamonu Üni., Orman Fakültesi Dergisi 2011; 11 (1): 52 - 67. 
[13] Karakuzu, E. Fesleğen (Ocimum basilicum L.) Tohumunun Ekim Olanakları. Yüksek lisans tezi. Adnan Menderes Üniversitesi Fen Bilimleri Enstitüsü 2015; Aydın.

[14] Kaşka, N., Yılmaz, M. Bahçe bitkileri Yetiştirme Tekniği. Çukurova Üniversitesi Ziraat Fakültesi Ders Kitabı, 1990.

[15] Murashige, T. and Skoog, F. A revised medium for rapid growth and bio assays with tobacco tissue cultures. Physiologia Plantarum 1962; 15(3), 473-497.

[16] Chua, K.J., Chou, S.K. A comparative study between intermittent microwave and infrared drying of Bioproducts. International journal of food science \& technology 2005; 40, 23-39.

[17] Phoungchandang, S., Kongpim, P. Modelıng Using A New Thin-Layer Drying Model And Drying Characteristics Of Sweet Basil (Ocimum baslicum L.) Using Tray And Heat Pump-Assisted Dehumidified Drying. Journal of Food Process Engineering 2011; 35, 851-862.

[18] Kalender M. Makine Sıva Alçısının İnce Tabaka Infrared Kuruma Kinetiği, Karakteristiği ve Modellenmesi. Fırat Üniversitesi Mühendislik Bilimleri Dergisi 2017; 29: 285-291.

[19] McCabe, W.L., Smith, J.C., Harriott, P. Unit operations of chemical engineering. McGraw-Hill New York, USA. 1993.

[20] Perry, J.H. Chemical engineers' handbook. Journal of Chemical Education 1950; 27, 533.

[21] Coulson, J.M. Coulson \& Richardson's chemical engineering. Butterworth-Heinemann, 1999. 